\title{
Growth of GaSb and GaInAsSb layers for thermophotovoltaic cells by liquid phase epitaxy
}

\author{
Lei Liu ${ }^{\mathrm{a} *}$, Nuofu Chen ${ }^{\mathrm{a}, \mathrm{b}}$, Fubao Gao ${ }^{\mathrm{a}}$, Zhigang Yin ${ }^{\mathrm{a}}, \mathrm{Min} \mathrm{Cui}^{\mathrm{a}}$, \\ Yiming Bai ${ }^{\mathrm{a}}$, Xingwang Zhang ${ }^{\mathrm{a}}$ \\ ${ }^{a}$ Key Laboratory of Semiconductor Materials Science, Institute of Semiconductors, Chinese \\ Academy of Sciences, POB 912, Beijing 100083, China \\ ${ }^{b}$ National Laboratory of Microgravity, Institute of Mechanics, Chinese Academy of Sciences, \\ Beijing 100080, China
}

\begin{abstract}
$\mathrm{GaSb}$ based cells as receivers in thermophotovoltaic system have attracted great interest and been extensively studied in the recent 15 years. Although nowadays the manufacturing technologies have made a great progress, there are still some details need to make a further study. In this paper, undoped and doped GaSb layers were grown on n-GaSb (100) substrates from both Ga-rich and Sb-rich solutions using liquid phase epitaxy (LPE) technique. The nominal segregation coefficients $k$ of intentional doped $\mathrm{Zn}$ were 1.4 and 8.8 determined from the two kinds of GaSb epitaxial layers. Additionally, compared with growing from Ga-rich solutions, the growing processes from Sb-rich solutions were much easier to control and the surface morphologies of epitaxial layers were smoother. Furthermore, in order to broaden the absorbing edge, $\mathrm{Ga}_{1-\mathrm{x}} \mathrm{In}_{\mathrm{x}} \mathrm{As}_{\mathrm{y}} \mathrm{Sb}_{1-\mathrm{y}}$ quaternary alloys were grown on both GaSb and InAs substrates from In-rich solutions, under different temperature respectively.
\end{abstract}

Keywords: thermophotovoltaic cell, LPE, segregation coefficient, GaSb, GaInAsSb

\section{INTRODUCTION}

Thermophotovoltaic (TPV) technology was firstly brought up in the early 1960s but did not make great progresses for a long time ${ }^{[1]}$. The renewal of interest in TPV technology started from 1990s because of the availability of highperformance cells based on III-V compound semiconductors. Among III-V compounds, gallium antimonide was the first material widely used as TPV receivers. $\mathrm{Ga}_{1-\mathrm{x}} \mathrm{In}_{\mathrm{x}} \mathrm{As}_{\mathrm{y}} \mathrm{Sb}_{1-\mathrm{y}}$ quaternary alloys lattice matched to $\mathrm{GaSb}$ and GaInAsP quaternary alloys lattice matched to InAs have been also developed for TPV cells ${ }^{[2,3]}$.

GaSb cells were first used as the bottom cells of mechanically stacked GaAs/GaSb solar cell. The technology used to fabricate $\mathrm{GaSb}$ cells was a simple process based on $\mathrm{Zn}$ vapour diffusion into n-type $\mathrm{GaSb}$ substrates. And no windows layer was fabricated on these GaSb cells because of the low surface recombination rate for p-type $\mathrm{GaSb}^{[3]}$. However, epitaxial methods such as liquid phase epitaxy (LPE), metalorganic vapour phase epitaxy (MOCVD) are indispensable for a more sophisticated cell structure. Liquid phase epitaxy is a well-established technology and widely used for III-V compound semiconductor devices because that it is simple, inexpensive and safe. Additionally, the high material quality that can be achieved is also an important advantage of LPE. In this paper, GaSb layers were grown on n-GaSb (100) substrates from both Ga-rich and Sb-rich solutions to form a p-n junction using liquid phase epitaxy technique. The growth process was discussed in detail.

$\mathrm{Ga}_{1-\mathrm{x}} \mathrm{In}_{\mathrm{x}} \mathrm{As}_{\mathrm{y}} \mathrm{Sb}_{1-\mathrm{y}}$ quaternary alloys have been widely studied as candidate materials for optoelectronic devices in the midinfrared wavelength range ${ }^{[4-7]}$. Comparing with the work based on $\mathrm{GaSb}$ substrates, there were only a few work that reported the growth of $\mathrm{Ga}_{1-x} \mathrm{In}_{\mathrm{x}} \mathrm{As}_{\mathrm{y}} \mathrm{Sb}_{1-\mathrm{y}}$ on InAs substrates ${ }^{[8,9]}$. Here, $\mathrm{Ga}_{1-\mathrm{x}} \mathrm{In}_{\mathrm{x}} \mathrm{As}_{\mathrm{y}} \mathrm{Sb}_{1-\mathrm{y}}$ quaternary alloys were grown on both $\mathrm{GaSb}$ and InAs substrates from In-rich solutions, under different temperature, respectively.

${ }^{*}$ Corresponding author. Tel.: +86-10-82304469; fax: +86-10-82304588. E-mail address: 1liu@semi.ac.cn

Solid State Lighting and Solar Energy Technologies, edited by Jinmin Li, Yubo Fan,

Ling Wu, Yong-Hang Zhang, Michael E. Coltrin, Yuwen Zhao, Nuofu Chen, Vladimir M. Andreev, Jai Singh,

Proc. of SPIE Vol. 6841, 68411E, (2007) · 0277-786X/07/\$18 · doi: 10.1117/12.755597

Proc. of SPIE Vol. $684168411 \mathrm{E}-1$ 


\section{EXPERIMENT}

$\mathrm{GaSb}$ and GaInAsSb epitaxial layers were grown by LPE using a conventional horizontal graphite sliding-boat system with an ambient of flowing Pd-diffusion hydrogen at atmospheric pressure. The substrates were $\mathrm{n}-\mathrm{GaSb}(100)$ and $\mathrm{n}$ InAs(100) with carrier concentrations of $1.9 \times 10^{17}$ and $2.2 \times 10^{16} \mathrm{~cm}^{-3}$, respectively. The GaSb and InAs substrates were $10 \times 10 \times 0.5 \mathrm{~mm}^{3}$ well-polished wafers, which were rinsed successively with tetrachloromethane, acetone, ethanol and deionized water in ultrasonic baths. And then the $\mathrm{GaSb}$ substrates were etched in a mixture solution of $\mathrm{CH}_{3} \mathrm{COOH}, \mathrm{H}_{2} \mathrm{O}$ and HF (20:9:1) before loading into the graphite boat. The InAs substrates were etached in a mixture solution of $\mathrm{H}_{2} \mathrm{O}_{2}$ and $\mathrm{HNO}_{3}(5: 3)$.

The starting materials were $6 \mathrm{~N}$ pure $\mathrm{In}, \mathrm{Ga}, \mathrm{Sb}$, and undoped polycrystalline GaAs. In the process of growing $\mathrm{GaSb}$ layers the Sb-rich solutions were homogenised and purified for $4 \mathrm{~h}$ at $700{ }^{\circ} \mathrm{C}$. After loading the wafers, the melt were heated to $620^{\circ} \mathrm{C}$ for $1 \mathrm{~h}$ to completely dissolve the growth solutions, then the temperature was reduced to $590^{\circ} \mathrm{C}$ at a cooling rate of $0.5^{\circ} \mathrm{C} / \mathrm{min}$. At $598^{\circ} \mathrm{C}$, the substrates were contacted with the melt for $10 \sim 60 \mathrm{~s}$ to grow GaSb layers. Garich solutions were used to grow GaSb epitaxial layers at $528^{\circ} \mathrm{C}$. For the $\mathrm{Ga}_{1-\mathrm{x}} \mathrm{In}_{\mathrm{x}} \mathrm{As}_{\mathrm{y}} \mathrm{Sb}_{1-\mathrm{y}}$ quaternary alloys, the LPE procedure was similar to that described above. The growth conditions and the liquid compositions are summarized in Table 1.

Structural properties of the epitaxial layers were evaluated by x-ray diffraction (XRD) and scanning electronic microscopy (SEM). Compositional analyses were characterized by energy dispersive $\mathrm{x}$-ray analysis (EDAX). And Fourier tansform infrared (FTIR) tansmission spectra of $\mathrm{Ga}_{1-\mathrm{x}} \mathrm{In}_{\mathrm{x}} \mathrm{As}_{\mathrm{y}} \mathrm{Sb}_{1-\mathrm{y}} / \mathrm{GaSb}$ layer was measured at room temperature using a GaSb substrate as reference. Electrochemical capacitance voltage was used to measure the carrier concentration of the epitaxial layers.

\section{RESULTS AND DISCUSSION}

One of the disadvantages for LPE is that it is difficult to control the growth rates, and thus, it is difficult to get epitaxial layers with thickness of the order of $100 \mathrm{~nm}$. In this paper the growth rates of the epitaxial layers are about $4 \mu \mathrm{m} \mathrm{min}$ and $7 \mu \mathrm{m} \mathrm{min}^{-1}$ form Ga-rich and Sb-rich solutions, respectively. It is known that the surface morphology and interface quality of epitaxial layers are related to growth conditions such as liquid composition and growth temperature. And the residual solution on the surface of the substrate is also a problem which would result in an unacceptable surface morphology. Compared with growing from Ga-rich solutions, it is easier to get a smooth surface without any residual solution from Sb-rich solutions. It is considered that the higher viscosity coefficient of the Sb-rich solutions than that of Ga-rich solutions at the growth temperature is responsible for the better surface condition. However, there were always pits on the GaSb epitaxial layers grown from Sb-rich solutions when the degree of supersaturation was less than $2^{\circ} \mathrm{C}$, asshown in Fig.1 $a$. These pits are often fatal defects which always result in short circuit for a TPV cell. And it was found that higher degree of supersaturation was necessary to get a smooth, mirror-like surface epitaxial layer. Fig. $1 b$ is the microphotograph of the surface morphology of a GaSb epitaxial layer grown from Sb-rich solution at a supersaturation degree of $7^{\circ} \mathrm{C}$.

Table 1. Summary of growth conditions and solid composition of the epitaxial layers

\begin{tabular}{cccccccccc}
\hline \multicolumn{2}{c}{ Liquid composition in atom fraction } & \multirow{2}{*}{$T_{l}$} & $\Delta T$ & $t(s)$ & $a(\mathrm{~nm})$ & \multicolumn{2}{c}{ Solid composition } \\
\cline { 1 - 2 } $\mathrm{In}$ & $\mathrm{Ga}$ & $\mathrm{As}$ & $\mathrm{Sb}$ & & & & & $\mathrm{x}$ & $\mathrm{y}$ \\
\hline 0 & 0.94 & 0 & 0.06 & 533 & 5 & 30 & - & - & - \\
0 & 0.135 & 0 & 0.865 & 605 & 7 & 30 & - & - & - \\
0.484 & 0.199 & 0.0029 & 0.314 & 600 & 5 & 30 & 0.6051 & 0.14 & 0.17 \\
0.585 & 0.169 & 0.0009 & 0.245 & 532 & 3 & 30 & 0.6085 & 0.16 & 0.14 \\
\hline
\end{tabular}

Undoped GaSb epitaxial layers grown from either Ga-rich solutions or Sb-rich solutions always show p-type conduction. The carrier concentration of the undoped GaSb epitaxial layers grown from Ga-rich and Sb-rich are $2.1 \times 10^{17} \mathrm{~cm}^{-3}$ and 8.3 $\times 10^{16} \mathrm{~cm}^{-3}$, respectively, measured by electrochemical capacitance voltage. It means that the doping is needless for the epitaxial layer grown from Ga-rich solution when it used as TPV cell. Anayama ${ }^{[10]}$ suggested that the carrier 
concentration of epitaxial layers depends strongly on the growth temperature, especially for that grown from Sb-rich solution. And relatively low carrier concentrations of the undoped GaSb epitaxial layers could be achieved at lower grown temperature. Additionally, $\mathrm{Zn}$ atoms were often used as intentional impurity in III-V compounds to form p-type conduction with carrier concentrations at given values. The nominal segregation coefficients $\mathrm{k}$ of intentional doped $\mathrm{Zn}$ were 1.4 and 8.8 determined from GaSb epitaxial layers and the two kinds of solutions.
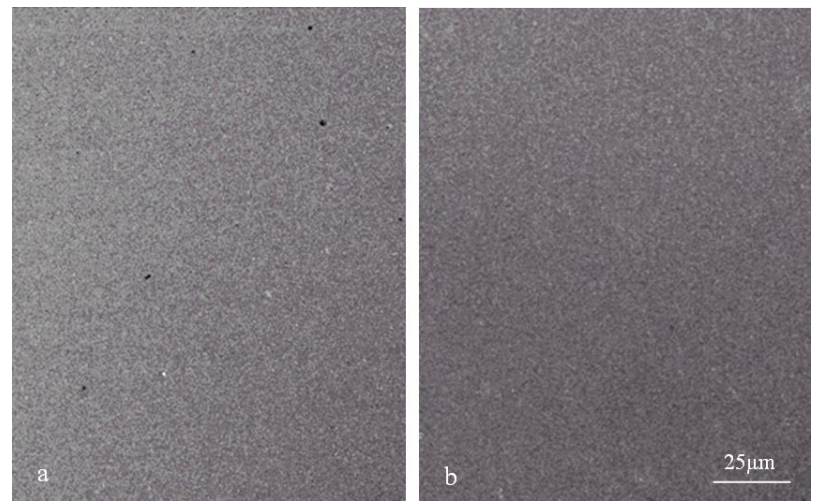

Fig.1. Microphotograph of the surface morphology of the GaSb epitaxial layers grown form Sb-rich solutions

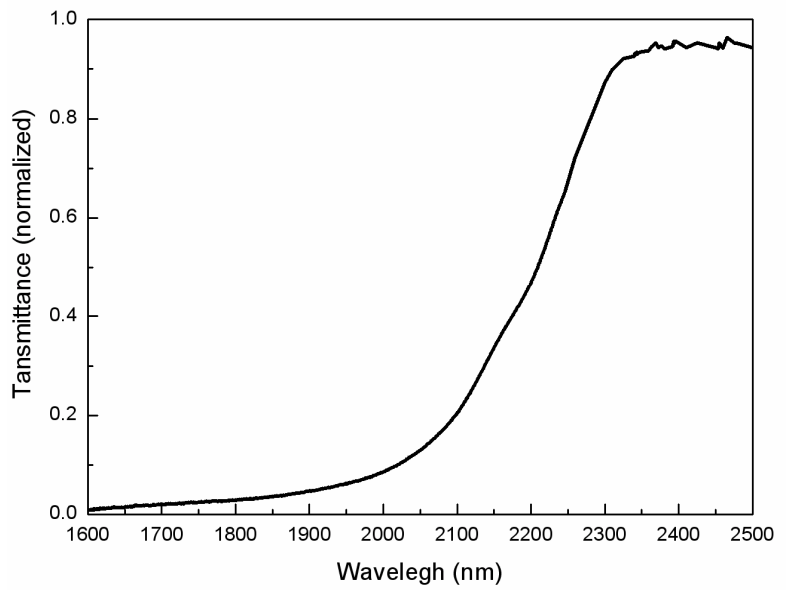

Fig.2. Fourier transform infrared transmission spectra at room temperature of the $\mathrm{Ga}_{0.84} \mathrm{In}_{0.16} \mathrm{As}_{0.14} \mathrm{Sb}_{0.86}$ epitaxial layer

Lattice matched $\mathrm{Ga}_{0.84} \mathrm{In}_{0.16} \mathrm{As}_{0.14} \mathrm{Sb}_{0.86}$ layer was successfully grown on GaSb (100) substrate with good surface morphology and straight ineterface line. The composition of the epitaxial layers was determined using EDAX. FTIR tansmission spectra of the $\mathrm{Ga}_{0.84} \mathrm{In}_{0.16} \mathrm{As}_{0.14} \mathrm{Sb}_{0.86}$ layer was obtained and is shown in Fig.2. If the cutoff wavelength is defined as midtransmittance wavelength, the cutoff wavelength $\lambda_{\mathrm{g}}$ of $\mathrm{Ga}_{0.84} \mathrm{In}_{0.16} \mathrm{As}_{0.14} \mathrm{Sb}_{0.86}$ would be $2208 \mathrm{~nm}$ corresponding to a band gap of $0.562 \mathrm{eV}$. The same liquid solution which was used to grown $\mathrm{Ga}_{0.84} \mathrm{In}_{0.16} \mathrm{As}_{0.14} \mathrm{Sb}_{0.86}$ layer on GaSb substrates was also tried to grow on InAs substrates. But no smooth surface of the epitaxial layers was achieved, although the lattice constants of InAs and $\mathrm{GaSb}$ are quite close. And then another liquid solution with a component of $\mathrm{X}_{\mathrm{In}}=0.484, \mathrm{X}_{\mathrm{Sb}}=0.314, \mathrm{X}_{\mathrm{As}}=0.0029$ was used to grow on InAs substrate.

Fig. 3 shows a cross section image of the $\mathrm{Ga}_{0.86} \mathrm{In}_{0.14} \mathrm{As}_{0.17} \mathrm{Sb}_{0.83} / \mathrm{InAs}$ observed under a scanning electron microscope. It is found that smooth, mirror-like surface could be achieved only for thin epitaxial film. By linescan of EDAX perpendicular to the surface in the cross section in Fig. 4, the distribution of the constituent elements along depth direction can be obtained and were shown in Fig. 5. The sharply changes of the distribution of the constituent elements at 
the interface demonstrate a good interface quality. FTIR tansmission spectra measurement is difficult to carry out for $\mathrm{Ga}_{0.86} \mathrm{In}_{0.14} \mathrm{As}_{0.17} \mathrm{Sb}_{0.83}$ epitaxial layer because of the existence of InAs substrate. A further study will be carried out to confirm the band gap of the two kinds of $\mathrm{Ga}_{1-\mathrm{x}} \mathrm{In}_{\mathrm{x}} \mathrm{As}_{\mathrm{y}} \mathrm{Sb}_{1-\mathrm{y}}$ alloys in future work.

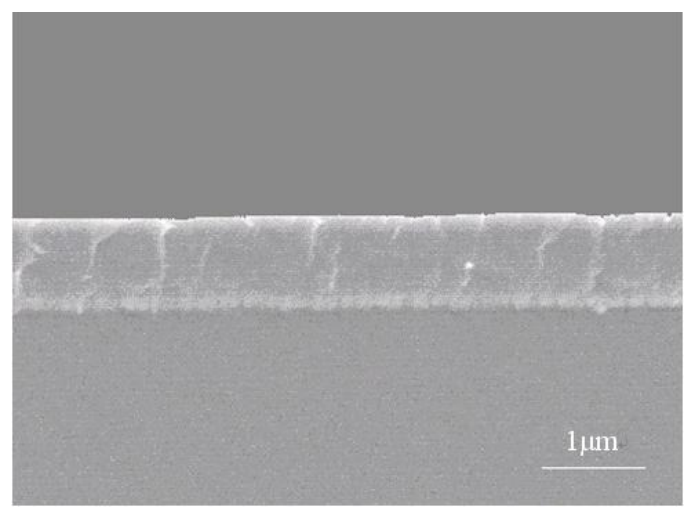

Fig. 3 Cross section SEM image of the $\mathrm{Ga}_{0.86} \mathrm{In}_{0.14} \mathrm{As}_{0.17} \mathrm{Sb}_{0.83}$ epitaxial layer

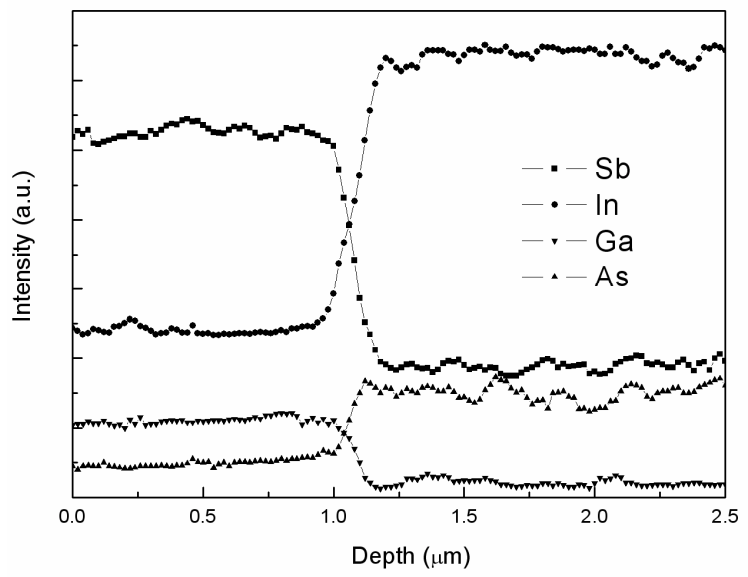

Fig.4 Distribution of the constituent elements along the depth direction obtained from EDAX linescan for the

$$
\mathrm{Ga}_{0.86} \mathrm{In}_{0.14} \mathrm{As}_{0.17} \mathrm{Sb}_{0.83} / \mathrm{InAs} \text { film }
$$

It is the same with GaSb epitxial layer that the undoped $\mathrm{Ga}_{1-\mathrm{x}} \mathrm{In}_{\mathrm{x}} \mathrm{As}_{\mathrm{y}} \mathrm{Sb}_{1-\mathrm{y}}$ layers also show p-type conduction. The carrier concentration of $\mathrm{Ga}_{0.84} \mathrm{In}_{0.16} \mathrm{As}_{0.14} \mathrm{Sb}_{0.86}$ and $\mathrm{Ga}_{0.86} \mathrm{In}_{0.14} \mathrm{As}_{0.17} \mathrm{Sb}_{0.83}$ layers were measured to be $7.9 \times 10^{17} \mathrm{~cm}^{-3}$ and $1.1 \times 10^{18}$ $\mathrm{cm}^{-3}$, respectively, which were a little higher for the requirements of device material.

\section{CONCLUSION}

LPE growths of GaSb and $\mathrm{Ga}_{1-x} \mathrm{In}_{\mathrm{x}} \mathrm{As}_{\mathrm{y}} \mathrm{Sb}_{1-\mathrm{y}}$ epitaxial layers used as TPV cells have been investigated. Both Ga-rich solution and Sb-rich solution have been used to grow GaSb layers. The results indicate that it is easier to get a smooth surface for the GaSb layer grown from Sb-rich solution than that form Ga-rich solution. The carrier concentration of the $\mathrm{GaSb}$ epitaxial layers were measured by electrochemical capacitance voltage. And the nominal segregation coefficients $\mathrm{k}$ of $\mathrm{Zn}$ atoms were determined to be 1.4 and 8.8 in the two kinds of solutions. $\mathrm{Ga}_{0.84} \mathrm{In}_{0.16} \mathrm{As}_{0.14} \mathrm{Sb}_{0.86}$ quaternary alloy was successfully grown on GaSb substrate. FTIR tansmission spectra of the $\mathrm{Ga}_{0.84} \mathrm{In}_{0.16} \mathrm{As}_{0.14} \mathrm{Sb}_{0.86}$ layer was meausured and indicated a cutoff wavelength $\lambda_{\mathrm{g}}$ of $2208 \mathrm{~nm}$. Shiny smooth $\mathrm{Ga}_{0.86} \mathrm{In}_{0.14} \mathrm{As}_{0.17} \mathrm{Sb}_{0.83}$ epitaxial layers were grown on InAs substrates. SEM image and EDAX linescan of the cross section show a good quality of the epitaxial layers. 


\section{REFERENCES}

1 Antonio Marti and Antonio Luque, Next Generation Phovoltaics, Chapter 11, Institute of Physics, Bristol and Philadelphia, 2004.

2 C. A. Wang, "Antimony-based III-V thermophotovoltaic materials and devices", Thermophotovoltaic Generation Of Electricity: Sixth Conference on Thermophotovoltaic Generation of Electricity, edited by A. Gopinath, T.J. Cooutts, and J. Juther, 738, (255-266), American Institute of Phyiscs, 2004.

3 A W Bett and O V Sulima, "GaSb photovoltaic cells for application in TPV generators", Semiconductor science and technology. 18, (184-190), 2003.

4 J. C. Dewinter, M. A. Pollack, A. K. Srivastava, and J. L. Zyskind, "Liquid phase epitaxial $\mathrm{Ga}_{1-\mathrm{x}} \mathrm{In}_{\mathrm{x}} \mathrm{As}_{\mathrm{y}} \mathrm{Sb}_{1-\mathrm{y}}$ latticematched To (100) GaSb over the 1.71 to $2.33 \mu \mathrm{m}$ wavelength range", Journal of electronic material, 14, (729-747), 1985.

5 Z. A. Shellenbarger, M. G. Mauk, J. A. cox, M. I. Gottfried, P. E. Sims, J. D. Lesko, J. B. Mcneely, and L. C. Dinetta, "Improvements in GaSb-Based Thermophotovoltaic Cells", Termophotovoltaic Generation of Electricty: Tird NREL conferece, edited by Benner/Coutts, 401, (117-128), American Institute of Phyiscs, 1997.

6 V. Rakovics, A. L. Toth, B. Podor, C. Frigeri, J. Balazs, Z. E. Horvath, "Liquid phase epitaxy growth and characterization of $\mathrm{Ga}_{1-\mathrm{x}} \mathrm{In}_{\mathrm{x}} \mathrm{As}_{\mathrm{y}} \mathrm{Sb}_{1-\mathrm{y}}$ quaternary alloys", Materials Science and Engineering, 91-92, (83-86), 2002.

7 M. G. Mauk and V. M. Andreev, "GaSb-related materials for TPV cells", Semiconductor science and technology, 18, (191-201), 2003.

8 R. Sankaran and G. A. Antypas, "Liquid phase epitaxial growth of InGaAsSb on (111)B InAs", Journal of crystal growth, 36, (198-204), 1976.

9 X. Y. Gong, Kan. H, Y. Tomou, Y. Takahiro, S. Isao, "Liquid Phase Epitaxial Growth of High-Quality GaInAsSb / InAs", Japanese journal of apply physics, 32, (711-715), 1993.

10 C. Anayama, T. Tanahashi, H. Kuwatsuka, S. Nishiyama, S. Isozumi, and K. Nakajima, "High-purity GaSb epitaxial layers grwon from Sb-sich solutions”, Apply physics letter, 56, (239-240), 1990. 